\title{
Electrosynthesis and Characterization of Polythiophene and Corrosion Protection for Stainless Steel
}

\author{
Yatang Dai ${ }^{1}$, Fanghua Zhu ${ }^{2}$, Huan Zhang ${ }^{1}$, Huan Ma ${ }^{1}$, Wei Wang ${ }^{1}$, Jiehong Lei ${ }^{3, *}$ \\ ${ }^{1}$ School of Materials Science and Engineering, Southwest University of Science and Technology, \\ Mianyang 621010, China. \\ ${ }^{2}$ Research Center of Laser Fusion, China Academy of Engineering Physics, Mianyang, Sichuan \\ 621900, China. \\ ${ }^{3}$ College of Physics and Space Science, China West Normal University, Nanchong 637009, \\ China. \\ *E-mail: jiehonglei@126.com
}

doi: $10.20964 / 110376$

Received: 16 January 2016 / Accepted: 27 February 2016 / Published: 1 April 2016

\begin{abstract}
Polythiophene (PTh) films were electrosynthesized on stainless steel (SS) in Boron trifluoride diethly etherate (BFEE) solution containing thiophene by potentiostatic method. The structure, morphology and thermostability of PTh films were studied by scanning electron microscopy (SEM) and UV-Vis diffuse. The corrosion protection behavior of the films were characterized in $3.5 \mathrm{wt} . \% \mathrm{NaCl}$ solution by linear potentiodynamic polarization (Tafel) and electrochemical impedance spectroscopy (EIS). It was found that after long immersion times $(779 \mathrm{~h})$, the best protection efficiency was $0.3 \mathrm{~mol}$ thiophene in BFEE potentiostatic synthesised $1.3 \mathrm{~V}$ for $1000 \mathrm{~s}$.
\end{abstract}

Keywords: Electrosynthesis; polythiophene; corrosion protection; stainless steel

\section{FULL TEXT}

(C) 2016 The Authors. Published by ESG (www.electrochemsci.org). This article is an open access article distributed under the terms and conditions of the Creative Commons Attribution license (http://creativecommons.org/licenses/by/4.0/). 